\title{
REDUÇÃO DA ADUBAÇÃO E MELHORIA DAS CARACTERÍSTICAS DO SUBSTRATO COM O USO DO HIDROGEL NA PRODUÇÃO DE MUDAS DE Eucalyptus dunnii Maiden
}

\author{
REDUCTION OF MANURE AND IMPROVEMENT OF THE CHARACTERISTICS OF SUBSTRATE \\ USING HYDROGEL IN THE SEEDLING PRODUCTION OF Eucalyptus dunnii Maiden
}

\author{
Marcio Carlos Navroski ${ }^{1}$ Maristela Machado Araújo ${ }^{2}$ Fernando da Silva Cunha ${ }^{3}$ \\ Álvaro Luís Pasquetti Berghetti ${ }^{4}$ Mariane de Oliveira Pereira ${ }^{5}$
}

\begin{abstract}
RESUMO
O objetivo do estudo foi avaliar se a presença do hidrogel afeta as propriedades físicas e químicas do substrato e a relação do hidrogel com doses de adubação no desenvolvimento de mudas. No substrato com presença e ausência do hidrogel foi realizada análise de características químicas e físicas. A produção de mudas foi conduzida em casa de vegetação sob irrigação reduzida, utilizando delineamento inteiramente casualizado em arranjo bifatorial 2 x 6 , em que os níveis do fator " $\mathrm{A}$ " referiram-se a presença $\left(6 \mathrm{~g} \mathrm{~L}^{-1}\right)$ ou ausência do hidrogel e os níveis do fator "B", às doses do fertilizante de liberação controlada - FLC (0; $25 ; 50 ; 75 ; 100$ e $125 \%$ da dose usual). Após 90 dias de semeadura foi realizada a avaliação de parâmetros morfológicos das mudas. O uso do hidrogel apresentou melhoria das características físicas e químicas do substrato, principalmente aos atributos que envolvem retenção e disponibilização de água às plantas. Com a adição do hidrogel e aproximadamente $50-75 \%$ da adubação convencional, houve aumento da altura, diâmetro de coleto, massa seca radicular e total, além do índice de qualidade de Dickson. Com o uso do hidrogel e adubação superior a 100\% há redução do crescimento das mudas. Já, sem a adição do polímero, o melhor desempenho das mudas é obtido com doses superiores a $100 \%$ da adubação convencional. Em geral, o uso do polímero permite a redução em, pelo menos, $25 \%$ da adubação convencional $\left(6 \mathrm{~g} \mathrm{~L}^{-1}\right)$, podendo ser reduzida em até $50 \%$.
\end{abstract}

Palavras-chave: produção de mudas; fertilizantes de liberação controlada; polímero hidrorretentor; economia de fertilizantes.

\section{ABSTRACT}

The aim of the study was to evaluate if the presence of hydrogel affects the physical and chemical properties of the substrate and the ratio of hydrogel in the fertilization rates of developing seedlings. In the substrate with and without hydrogel, it was carried out an analysis for the chemical and physical characteristics. The production of seedlings was conducted in a greenhouse under reduced irrigation using a randomized design factorial arrangement $2 \times 6$ in which the levels of factor ' $A$ ' referred to the presence $\left(6 \mathrm{~g} \mathrm{~L}^{-1}\right)$ or absence of hydrogel and the levels of factor ' $\mathrm{B}$ ' to the doses of controlled-release fertilizer - FLC

1 Engenheiro Florestal, Dr, Professor do Departamento de Engenharia Florestal, Centro de Ciências Agroveterinárias, Universidade do Estado de Santa Catarina, Av. Luiz de Camões, 2090, CEP 88520-000, Lages (SC), Brasil. marcio. navroski@udesc.br

2 Engenheira Florestal, Dra ${ }^{\mathrm{a}}$, Professora Adjunta do Departamento de Ciências Florestais, Centro de Ciências Rurais, Universidade Federal de Santa Maria, Av. Roraima, 1000, CEP 97105-900, Santa Maria (RS), Brasil. araujo. maristela@gmail.com

3 Engenheiro Florestal, Centro de Ciências Rurais, Universidade Federal de Santa Maria, Av. Roraima, 1000, CEP 97105-900, Santa Maria (RS), Brasil. fernando_berasm@yahoo.com.br

4 Engenheiro Florestal, Centro de Ciências Rurais, Universidade Federal de Santa Maria, Av. Roraima, 1000, CEP 97105-900, Santa Maria (RS), Brasil. alvaro.berghetti@gmail.com

5 Engenheira Florestal, Doutoranda do Programa de Pós-Graduação em Engenharia Florestal, Universidade Federal do Paraná, Av. Pref. Lothário Meissner, 900, Jardim Botânico, CEP 80210-170, Curitiba (PR), Brasil. maripereira.florestal@gmail.com

Recebido para publicação em 13/11/2013 e aceito em 16/01/2015 
$(0 ; 25 ; 50 ; 75 ; 100$ and $125 \%$ of the usual dosage). After 90 days of sowing, there was the evaluation of morphological parameters of seedlings. The use of hydrogel showed improvement of physical and chemical characteristics of the substrate, especially the attributes involving water retention and availability of the plants. Together with the addition of hydrogel and approximately $50-75 \%$ of conventional fertilization, there was an increase in height, diameter collect, dry mass, root and all, in addition to the Dickson Quality Index. Along with the use of hydrogel and fertilization over 100\%, the growth of seedlings decreased. On the other hand, without the addition of the polymer, the best performance was obtained from seedlings at doses higher than $100 \%$ of conventional fertilization. In general, the use of the polymer allows a reduction of at least $25 \%$ of the conventional fertilization $\left(6 \mathrm{~g} \mathrm{~L}^{-1}\right)$, reaching up to $50 \%$.

Keywords: seedling production; controlled release fertilizers; polymer hidroretentor; saving of fertilizer.

\section{INTRODUÇÃO}

O Eucalyptus dunnii Maiden tem se destacado na região Sul do Brasil, devido ao seu rápido crescimento e tolerância a injúrias causadas por geadas. Segundo Paludzyszyn Filho et al. (2006), as espécies de eucalipto economicamente importantes para as condições mais frias do Brasil constituem um grupo muito restrito e, entre eles, Eucalyptus dunnii apresenta boa aptidão, principalmente no que se refere à produção de madeira para fins energéticos e sólidos madeiráveis.

A produção de mudas sadias e bem desenvolvidas é um fator de extrema importância para qualquer cultura, principalmente para aquelas que apresentam caráter perene, como é o caso do eucalipto. Quando esta etapa é bem conduzida tem-se uma atividade mais sustentável, com maior produtividade e com menor custo.

Para a produção de mudas de qualidade superior é necessário investigar as técnicas mais adequadas utilizadas em viveiro, as quais corresponderão às maiores taxas de sobrevivência e ao crescimento inicial no pós-plantio. A demanda por mudas de qualidade e de crescimento rápido tem sido crescente, resultado da tecnologia de produção que está em constante evolução para os reflorestamentos (HAASE, 2008).

A fertilização é uma das práticas mais importantes na produção de mudas, especialmente quando as plantas são produzidas em recipientes, limitando o seu crescimento (LANDIS, 1989). Essa variável cultural pode acelerar ou diminuir o crescimento da planta, alterar a composição nutritiva dos tecidos, tendo efeitos sobre os níveis de reserva, resistência ao estresse hídrico, frio e doenças, afetando todos os atributos de qualidade de uma muda florestal (OLIET et al., 1999). A eficiência das adubações depende basicamente das doses e fontes dos adubos utilizados, da capacidade de troca catiônica e das características físicas do substrato (SGARBI et al., 1999), podendo ainda ser influenciada por uso de aditivos, como polímeros hidrorretentores (AZEVEDO et al., 2002; GEESING; SCHMIDHALTER, 2004).

Os polímeros hidrorretentores, também chamado de géis hidrorretentores ou de hidrogéis são caracterizados pela capacidade de absorver e liberar água e nutrientes solúveis. A natureza do arranjo das moléculas confere a esse material uma forma granular quando seco e, ao ser hidratado, os grânulos dilatam-se, transformando-se em partículas de gel (PREVEDELLO; BALENA, 2000).

O polímero vem sendo comercializado com as justificativas de que, ao ser incorporado ao substrato, permite maior retenção de água e de fertilizantes, que podem ser liberados mais lentamente para as plantas em função dos ciclos absorção - liberação (BERNARDI et al., 2012). Além disso, segundo Taylor e Halfacre (1986), a adição de hidrogel, em função de sua elevada capacidade de troca catiônica (CTC), reduz a lixiviação de nutrientes.

Tais polímeros devem ser cuidadosamente avaliados, em cada campo de utilização, tendo em vista os efeitos secundários potencialmente adversos que podem estar associados. Em casos de excesso de sais e nutrientes no substrato, a adição do polímero pode ter pouca influência no crescimento e desenvolvimento das plantas, podendo até se tornar prejudicial (PETERSON, 2003).

Portanto, o fornecimento adequado de água e nutrientes, contribuem, de forma expressiva, tanto no aumento da produtividade como no aumento da produção. Nessa situação, a otimização da eficiência do uso da água e nutrientes é fundamental para ampliar a produtividade e reduzir o custo de produção (FAGERIA, 1998).

Uma opção seria a utilização de hidrogéis como veículos carreadores para liberação controlada, 
pois liberam água e nutrientes paulatinamente, retardando e, consequentemente, diminuindo sua perda no perfil do solo. Essas características podem ser atribuídas ao fato de que a presença de hidrogel pode modificar propriedades físicas adversas do solo, como baixa capacidade de retenção de água e excessiva permeabilidade (SHAVIV, 2001).

Desta forma, objetivou-se avaliar se a presença do hidrogel afeta as propriedades físicas e químicas do substrato e a relação do hidrogel com doses de adubação no crescimento de mudas de Eucalyptus dunnii Maiden.

\section{MATERIAL E MÉTODO}

$\mathrm{O}$ experimento foi realizado em delineamento inteiramente casualizado, em esquema bifatorial 2 x 6 , em que os níveis do fator " $A$ " referiram-se à presença $\left(6 \mathrm{~g} \mathrm{~L}^{-1}\right.$ de substrato) e ausência de hidrogel, e os níveis do fator " $B$ ", às doses do fertilizante de liberação controlada - FLC $(0 ; 1,5 ; 3 ; 4,5 ; 6$ e 7,5 $\mathrm{g} \mathrm{L}^{-1}$ de substrato correspondendo a $0 ; 25 ; 50 ; 75$; 100 e $125 \%$ da dose recomendada por Bernardi et al. (2012)). Foram utilizadas 6 repetições, cada uma composta por 24 plantas, sendo posteriormente consideradas para avaliação as 8 plantas centrais de cada parcela.

Para a instalação do experimento, foram utilizados tubetes com a capacidade de $110 \mathrm{~cm}^{3}$. Ao substrato foi adicionado polímero hidrorretentor e adubação. A adubação de base utilizada foi composta de fertilizante de liberação controlada (FLC) na formulação NPK 18-5-9, sendo utilizada a concentração conforme o tratamento. Segundo as especificações técnicas do fabricante, quando colocado em substrato úmido, a uma temperatura média de $21,1^{\circ} \mathrm{C}$, a liberação de todos nutrientes ocorre dentro de um prazo de 5 e 6 meses.

O substrato utilizado foi de origem comercial $\left(\right.$ Carolina Soil $\left.{ }^{\circledR}\right)$ composto à base de turfa de Sphagno, vermiculita expandida, calcário dolomítico, gesso agrícola e fertilizante NPK. O polímero comercial $\left(\right.$ Hydroplan $^{\circledR}$ ) utilizado correspondeu a um produto misto de copolímero de acrilamida $\left(\mathrm{C}_{3} \mathrm{H}_{5} \mathrm{NO}\right)$ e acrilato de potássio $\left(\mathrm{K}_{2} \mathrm{~S}_{2} \mathrm{O}_{8}\right)$ usado para absorver e reter grandes quantidades de água e nutrientes, com as seguintes características: pó branco insolúvel em água, com partículas de tamanho que variam de 0,3 a $1,0 \mathrm{~mm}$, aniônico, com $10 \%$ de umidade, densidade de $0,8 \mathrm{~g} \mathrm{~cm}^{-3} \mathrm{e}$ índice de $\mathrm{pH}$ utilizável de 5 a 9 , que pode disponibilizar até $95 \%$ da solução armazenada para a planta ( $5 \%$ retidos a alta tensão), capaz de absorver até 300 vezes sua massa em água e 100 vezes seu volume, sendo compatível com a maioria dos insumos utilizados.

Para proporcionar uma mistura homogênea e garantir uma boa distribuição do polímero e do fertilizante ao substrato, as misturas foram preparadas em porções de 5 litros. Após a mistura do polímero e do fertilizante ao substrato, procedeuse o preenchimento dos tubetes conforme cada tratamento, dispostos nas bandejas e, em seguida submetidos à mesa vibratória por aproximadamente 10 segundos. Buscou-se um preenchimento dos tubetes em aproximadamente $80 \%$ do volume máximo possível, para evitar derramamento do substrato após a hidratação com o hidrogel, devido à expansão das partículas do hidrorretentor durante a sua hidratação. Foram utilizadas sementes de Eucalyptus dunnii originárias de Área de Produção de Sementes, que, segundo informações da empresa fornecedora apresentam pureza de $90 \%$ e porcentagem de geminação média de $80 \%$.

A semeadura foi efetuada colocando-se uma ou duas sementes em cada recipiente, as quais foram cobertas com uma fina camada de vermiculita fina. Após a semeadura, as bandejas com os tubetes foram levadas à casa de vegetação, na qual permaneceram até a avaliação do experimento (90 dias). Com 40 dias, procedeu-se o raleio das mudas, permanecendo a mais vigorosa e centralizada no recipiente. Aos 60 dias procedeu-se a diminuição da densidade das mudas na bandeja em $50 \%$, passando da densidade inicial de 400 plantas $/ \mathrm{m}^{2}$ para 200 plantas $/ \mathrm{m}^{2}$. A irrigação foi realizada por uma barra de irrigação composta por aspersores do tipo microaspersão, com uma lâmina de $4 \mathrm{~mm} /$ dia, divididos em 4 horários, sendo acionada por um timer às $8 \mathrm{~h}$, às $11 \mathrm{~h}$, às $14 \mathrm{~h} \mathrm{e}$ às $17 \mathrm{~h}$.

A avaliação foi efetuada aos 90 dias após a semeadura, através das seguintes variáveis: altura da parte aérea (desde o coleto até o ápice do caule) $(\mathrm{H})$, diâmetro do coleto (DC), massa seca da parte aérea (MSPA), massa seca radicular (MSR), massa seca total (MST). Também foi calculado o Índice de Qualidade de Dickson (IQD), o qual é determinado em função da altura da parte aérea $(\mathrm{H})$, do diâmetro do colo (DC), massa seca da parte aérea (MSPA) que é dada pela soma da massa seca do colo e das folhas e da massa seca de raízes (MSR), por meio da fórmula (DICKSON et al., 1960):

$$
\mathrm{IQD}=\frac{\mathrm{MST}(\mathrm{g})}{\frac{\mathrm{H}(\mathrm{cm})}{\mathrm{DC}(\mathrm{mm})}+\frac{\operatorname{MSPA}(\mathrm{g})}{\operatorname{MSR}(\mathrm{g})}}
$$


As mudas foram cortadas e separadas em parte aérea e radicular. A parte radicular contendo o substrato foi lavada em água corrente e, com auxílio de peneiras, foi efetuada a separação das raízes. Tanto as raízes quanto a parte aérea foram secas em estufa com temperatura de $70^{\circ} \mathrm{C}$ até atingirem peso constante, sendo após pesadas em balança de precisão.

A caracterização física e química dos substratos com as respectivas misturas de hidrorretentor, conforme os tratamentos, foram realizadas no Laboratório de Substratos do Departamento de Horticultura e Silvicultura da Universidade Federal do Rio Grande do Sul, conforme a Instrução Normativa $\mathrm{n}^{\circ} 17$ do Ministério da Agricultura, Pecuária e Abastecimento (BRASIL, 2007) e Fermino (2003).

Dentre os atributos físicos relativos à densidade e umidade do substrato foram avaliadas a densidade úmida - DU $\left(\mathrm{kg} \mathrm{m}^{-3}\right)$; densidade seca - DS $\left(\mathrm{kg} \mathrm{m}^{-3}\right)$ e a umidade atual - UA (\%). As determinações do espaço de aeração e água disponível foram realizadas através do uso de funis de tensão, com $0,10,50$ e $100 \mathrm{~cm}$ de coluna de água, correspondendo às tensões de $0 ; 1 ; 5$ e $10 \mathrm{kPa}$. Após os procedimentos laboratoriais foram obtidas as seguintes variáveis (todas expressas em \%): porosidade total, que corresponde umidade presente nas amostras saturadas sob tensão $0 \mathrm{kPa}$; espaço de aeração (EA), que é a diferença entre a porosidade total e o volume de água retida na tensão de $1 \mathrm{kPa}$; água disponível (AD), que é o volume de água entre as tensões de $1 \mathrm{kPa}$ e $10 \mathrm{kPa}$; água remanescente (AR), que é o volume de água no material após ter sido submetido à tensão de $10 \mathrm{kPa}$ e Capacidade de Retenção de Água (CRA) é a quantidade de água retida por um substrato após ser submetido a uma determinada tensão.

Os atributos químicos analisados foram a condutividade elétrica e o $\mathrm{pH}$, com o uso de condutivímetro e potenciômetro (pHmetro), respectivamente. Para ambas as determinações utilizou-se a diluição de 1:5 (v/v), com água deionizada. Foram também realizadas análises de $\mathrm{pH}$, de condutividade elétrica e de teor total de sais solúveis (TTSS) em amostras de areia lavada com a adição do hidrogel (em cada dosagem). $\mathrm{O}$ pH e a condutividade elétrica foram analisadas da mesma forma que o substrato. Já o teor total de sais solúveis (TTSS) das amostras foi determinado considerando a $\mathrm{CE}\left(\mathrm{mS} \mathrm{cm} \mathrm{cm}^{-1}\right)$ e a densidade do material, em suspensão areia:água deionizada na proporção de $1: 10(\mathrm{~m} / \mathrm{v})$, expressa como teor de $\mathrm{KCl}$ (RÖBER;
SCHALLER, 1985) de acordo com a seguinte fórmula:

$$
\operatorname{TTSS}\left(\mathrm{g} \mathrm{L}^{-1}\right)=\frac{\mathrm{X} * \mathrm{C} * 56,312 * \mathrm{DU} / 100}{100.000}
$$

Sendo:

$\mathrm{X}$ : leitura do condutivímetro em Siemens x $10^{-4}$;

$\mathrm{C}$ : constante da célula do condutivímetro $=1$ para aparelhos com correção automática de temperatura; 56,312: fator de correção para expressar a condutividade em $\mathrm{mg}$ de $\mathrm{KCl} / 100 \mathrm{~g}$ de substrato $\left(25^{\circ} \mathrm{C}\right)$;

DU: densidade úmida $\left(\mathrm{kg} \mathrm{m}^{-3}\right)$;

100.000: fator de conversão das unidades para $\mathrm{kg}$ $\mathrm{m}^{-3}\left(=\mathrm{g} \mathrm{L}^{-1}\right)$.

Após confirmada a normalidade e a homocedasticidade dos dados das variáveis analisadas foi realizada análise de variância paramétrica. Quando necessário, realizou-se o desdobramento das interações, sendo as médias pelo teste de Scott-Knott e/ou regressão polinomial a $5 \%$ de probabilidade de erro. No caso de efeito significativo de equações quadráticas, determinouse o ponto de máxima eficiência técnica (MET). Para as análises, foi utilizado o pacote estatístico SISVAR (FERREIRA, 2011).

\section{RESULTADOS E DISCUSSÃO}

\section{Análise de substrato e hidrogel}

A Tabela 1 contém os resultados da análise realizada no substrato comercial (Carolina Soil ${ }^{\circledR}$ ) na comparação entre a adição ou não do hidrogel. A exceção da densidade seca (DS), todos os demais atributos analisados apresentaram diferença quanto ao polímero.

A densidade úmida (DU), a umidade atual (UA) e a porosidade total (PT) aumentaram com a adição do hidrogel. $\mathrm{O}$ aumento da densidade úmida e da umidade atual é esperado devido à hidratação do hidrogel sob pequena disponibilidade de água já presente no substrato.

O aumento da porosidade total ocorre, provavelmente, devido à expansão das partículas do polímero. Conforme os valores indicados como adequados por Gonçalves e Poggiani (1996), a porosidade total do substrato sem adição do hidrogel encontra-se dentro da faixa considerada adequada, a qual varia entre 75 e $85 \%$. Já com a adição do hidrogel, a porosidade total está acima do 
TABELA 1: Análise do substrato comercial (Carolina Soil ${ }^{\circledR}$ ) na presença e ausência de hidrogel utilizado para a produção de mudas de Eucalyptus dunnii.

TABLE 1: Analysis of commercial substrate $\left(\right.$ Carolina Soil $\left.{ }^{\circledR}\right)$ in the presence and absence of hydrogel used for the production of Eucalyptus dunnii seedlings.

\begin{tabular}{lcc}
\hline \multicolumn{1}{c}{ Atributos analisados } & Ausência hidrogel $\left(0 \mathrm{~g} \mathrm{~L}^{-1}\right)$ & Presença hidrogel $\left(6 \mathrm{~g} \mathrm{~L}^{-1}\right)$ \\
\hline DU $\left(\mathrm{kg} \mathrm{m}^{-3}\right)$ & $211,93 \mathrm{~b}$ & $237,60 \mathrm{a}$ \\
DS $\left(\mathrm{kg} \mathrm{m}^{-3}\right)$ & $113,62^{\mathrm{ns}}$ & $110,29^{\mathrm{ns}}$ \\
$\mathrm{UA}(\%)$ & $46,38 \mathrm{~b}$ & $53,58 \mathrm{a}$ \\
PT $(\%)$ & $80,81 \mathrm{~b}$ & $98,00 \mathrm{a}$ \\
EA $(\%)$ & $25,33 \mathrm{a}$ & $19,35 \mathrm{~b}$ \\
AD $(\%)$ & $22,61 \mathrm{~b}$ & $33,31 \mathrm{a}$ \\
AFD $(\%)$ & $19,07 \mathrm{~b}$ & $28,23 \mathrm{a}$ \\
AT $(\%)$ & $3,54 \mathrm{~b}$ & $5,08 \mathrm{a}$ \\
AR $(\%)$ & $32,86 \mathrm{~b}$ & $45,33 \mathrm{a}$ \\
CRA1 $(\%)$ & $55,48 \mathrm{~b}$ & $78,64 \mathrm{a}$ \\
CRA5 $(\%)$ & $36,40 \mathrm{~b}$ & $50,41 \mathrm{a}$ \\
CRA10 $(\%)$ & $32,86 \mathrm{~b}$ & $45,33 \mathrm{a}$ \\
pH & $4,87 \mathrm{~b}$ & $6,31 \mathrm{a}$ \\
CE $(\mathrm{mS} \mathrm{cm}-1)$ & $0,46 \mathrm{~b}$ & $0,59 \mathrm{a}$ \\
\hline
\end{tabular}

Em que: $\mathrm{DU}=$ densidade úmida; $\mathrm{DS}=$ densidade seca; $\mathrm{UA}=$ umidade atual; $\mathrm{PT}=$ porosidade total; $\mathrm{EA}=$ espaço de aeração; $\mathrm{AFD}$ = água facilmente disponível; $\mathrm{AT}$ = água tamponante; $\mathrm{AR}$ = água remanescente; CRA1, CRA5 e CRA10 = capacidade de retenção de água correspondendo às tensões de 1,5 e $10 \mathrm{kPa}$. $\mathrm{CE}=$ condutividade elétrica. Médias seguidas pela mesma letra na linha, não diferem entre si pelo teste " $\mathrm{t}$ " ao nível de $5 \%$ de probabilidade de erro; ns $=$ não significativo.

adequado, apesar de não ter proporcionado prejuízo ao desenvolvimento da planta. Segundo Kämpf (2005), a porosidade é de fundamental importância para o crescimento das plantas, visto que a alta concentração de raízes formadas nos recipientes exigem elevado fornecimento de oxigênio e rápida remoção do gás carbônico formado.

Apesar da maior porosidade total, o espaço de aeração ou macroporosidade diminuiu com a adição do hidrogel. Este resultado foi provavelmente causado pelo preenchimento dos maiores poros no substrato com a hidratação do hidrogel. Para ambas as situações, o espaço de aeração está abaixo do considerado ideal por Gonçalves e Poggiani (1996), no qual situa-se na faixa entre $35-45 \%$.

Quanto à água disponível (AD), água facilmente disponível (AFD), água tamponante (AT) e água remanescente (AR), a adição do hidrogel provocou aumento dos níveis em todos os atributos, mostrando que o hidrogel aumenta a disponibilidade de água no substrato. Segundo Abad et al. (1993), em condições ótimas, o substrato ideal deve apresentar entre 20 e $30 \%$ de água facilmente disponível (AFD), entre 4 e 10\% de água tamponante (AT) e entre 24 e $40 \%$ de água disponível (AD) para as plantas. Com base no autor supracitado para todos estes atributos, a presença do hidrogel proporcionou faixa mais adequada em comparação ao substrato sem o hidrogel. Segundo Zanetti et al. (2003), o aumento da disponibilidade de água no substrato pode reduzir a quantidade de água na irrigação, ou a frequência de irrigação.

Para a capacidade de retenção de água, em todas as colunas de sucções avaliadas, houve aumento da retenção com o hidrogel adicionado ao substrato (Figura 1). Substratos com menor capacidade de retenção de água exigem maior aplicação de água em cada irrigação, ou que seja aumentada a frequência da mesma (WENDLING et al., 2006). Desta forma, substratos com maior capacidade de retenção de água requerem maior controle de irrigação, com o intuito de evitar o encharcamento (GONÇALVES et al., 2000).

Corroborando esse resultado, Flannery e Busscher (1982), trabalhando com as culturas de Rhododendron simsii e Secale cereale, 


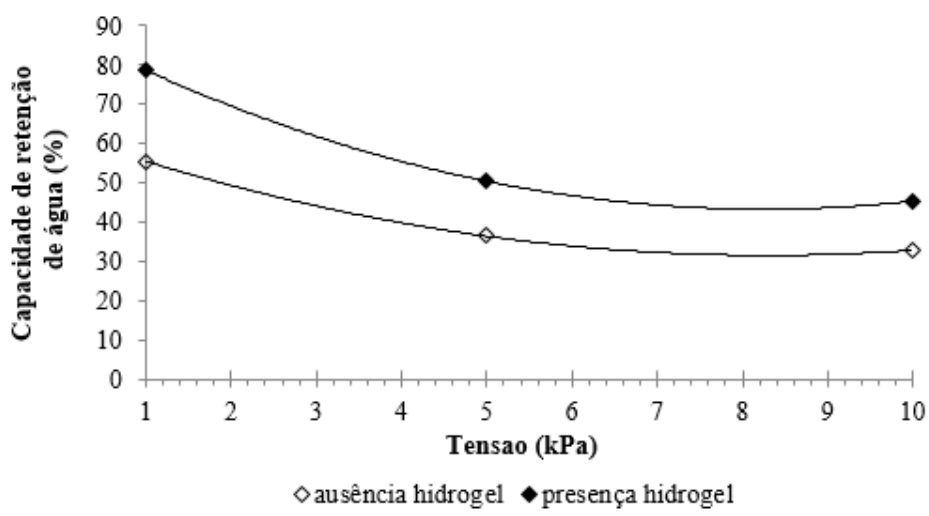

FIGURA 1: Curva característica de retenção de água do substrato comercial Carolina Soil ${ }^{\circledR}$ na presença (6 $\left.\mathrm{g} \mathrm{L}^{-1}\right)$ e ausência $\left(0 \mathrm{~g} \mathrm{~L}^{-1}\right)$ do hidrogel submetido às tensões 1,5 e $10 \mathrm{kPa}$.

FIGURE 1: Characteristic curve of water retention of the commercial substrate Carolina Soil ${ }^{\circledR}$ in the presence $\left(6 \mathrm{~g} \mathrm{~L}^{-1}\right)$ and absence $\left(0 \mathrm{~g} \mathrm{~L}^{-1}\right)$ of hydrogel subjected to stresses 1.5 and $10 \mathrm{kPa}$.

demonstraram que ao adicionar polímero no substrato de cultivo, elevou-se a capacidade de retenção de água desse substrato e grande quantidade dessa água armazenada pelo hidrogel ficou prontamente disponível para as plantas, contribuindo para a diminuição da frequência e quantidade total das irrigações. Essa capacidade de aproveitamento de água do hidrogel pelas plantas ocorre em função da superfície de contato das raízes com os grânulos de hidrogel hidratado.

Em relação à análise química do substrato, o pH apresentou aumento com a adição do hidrogel, assim como a condutividade elétrica (Tabela 1). $\mathrm{O}$ pH encontrado para o substrato com adição do hidrogel está dentro do limite considerado adequado, o qual, segundo Gonçalves e Poggiani (1996), para as espécies florestais, varia entre 5,5 e 6,5. Em substratos com $\mathrm{pH}$ abaixo de 5,0 pode ocorrer a deficiência de nitrogênio, potássio, cálcio, magnésio e boro, enquanto que em $\mathrm{pH}$ acima de 6,5 são esperados deficiências de fósforo, ferro, manganês, zinco e cobre (VALERI; CORRADINI, 2000).

O aumento da condutividade é um indicativo da concentração de sais no substrato e, segundo Kämpf (2005) é um parâmetro que informa a salinidade do substrato. $\mathrm{O}$ aumento da retenção de água e nutrientes pode ser a causa da elevação do teor de sais no meio. Os valores adequados da condutividade elétrica do substrato variam entre espécies, cultivares e clones. Em geral, para as espécies florestais, ela deve estar entre 1,5 a 3,0 mS $\mathrm{cm}^{-1}$.
A elevação desses atributos com o hidrogel possivelmente seja em função das características do polímero. A análise de $\mathrm{pH}$ das amostras de areia lavada indicam um grande aumento do $\mathrm{pH}$ com a adição do hidrogel, passando de 6,02 na ausência do hidrogel para 8,93 na presença de $6 \mathrm{~g} \mathrm{~L}^{-1}$. A condutividade elétrica (CE) e o teor total de sais solúveis (TTSS) também apresentaram um grande aumento com a adição do hidrogel, a CE variou de 0,01 para $0,243 \mathrm{mS} \mathrm{cm}^{-1}$, já o TTSS de 0,037 para $0,587 \mathrm{~g} \mathrm{~L}^{-1}$.

\section{Crescimento inicial das mudas}

A análise de variância dos dados medidos aos 90 dias após semeadura mostrou que não houve diferença significativa entre os tratamentos $(p>0,05)$ para a relação H/DC. A maioria das variáveis avaliadas (H, DC, MSPA, MSR e MST) apresentaram interação $(p<0,05)$ entre os fatores, enquanto o índice de qualidade de Dickson obteve efeito significativo somente para os fatores isolados (hidrogel $p<0,0001$ e dose FLC $p=0,0069$ ).

A altura das mudas de Eucalyptus dunnii foi influenciada pela dosagem de fertilizante utilizada e também pelo gel hidrorretentor (Figura 2A). A presença do hidrogel possibilitou ganho considerável de altura, principalmente nas menores dosagens de adubação. Maior altura das mudas na presença do hidrogel foi obtida com a dosagem de $3 \mathrm{~g} \mathrm{~L}^{-1}$ de adubo, o equivalente a $50 \%$ da dosagem convencional. Já na ausência do hidrogel há uma tendência de aumento da altura com o aumento da 

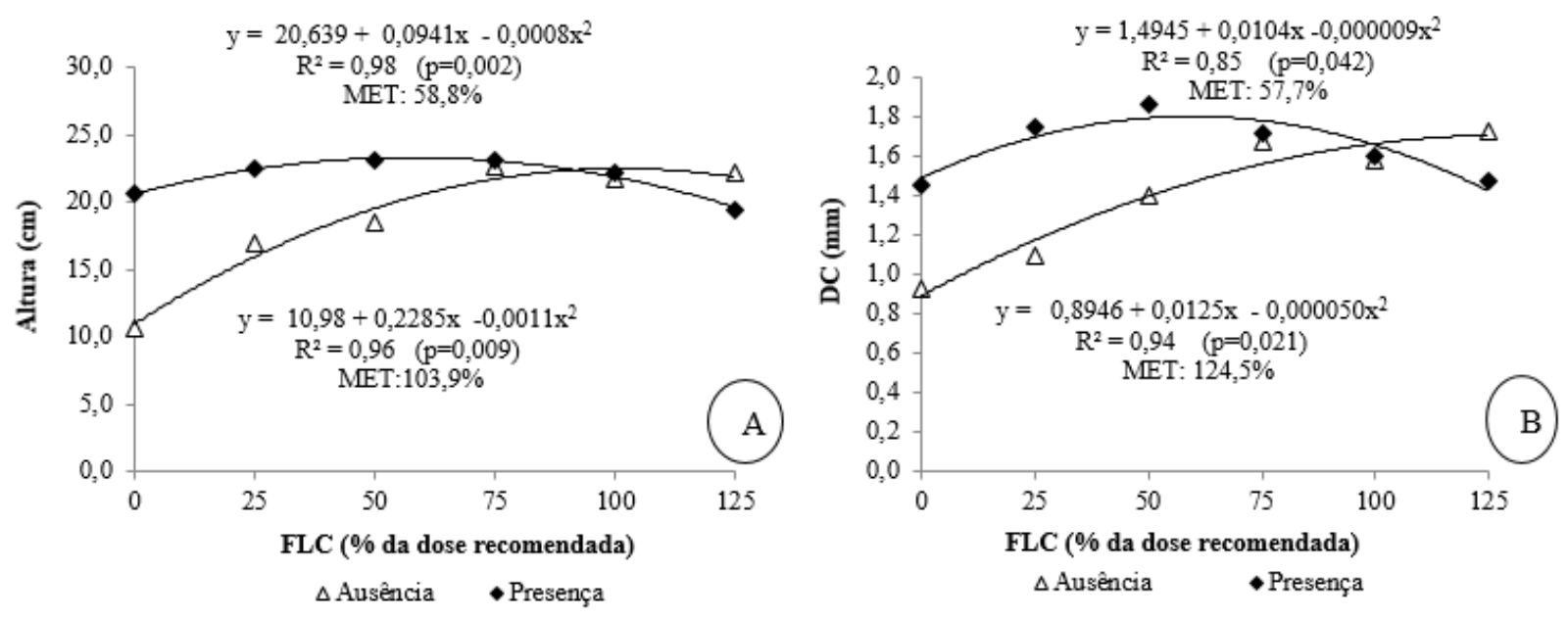

FIGURA 2: A- Altura (H); B - Diâmetro de colo (DC) das mudas de Eucalyptus dunnii em função das doses de fertilizante (\% da dose recomendada) na presença $\left(6 \mathrm{~g} \mathrm{~L}^{-1}\right)$ e ausência de hidrogel, aos 90 dias após semeadura.

FIGURE 2: A- Height (h), B - stem diameter (DC) of seedlings of Eucalyptus dunnii depending on the fertilizer rates (\% of the recommended dose) in the presence $\left(6 \mathrm{~g} \mathrm{~L}^{-1}\right)$ and absence of hydrogel at 90 days after sowing.

dose do FLC.

Calculados os pontos de máxima eficiência técnica de ambas as equações, obtiveram-se, respectivamente, para presença e ausência de hidrogel, os valores de $58,8 \%$ e $103,9 \%$ da dosagem do fertilizante. Acima desta dose há diminuição da altura das mudas. Observou-se uma tendência de redução da altura no uso do hidrogel quando a adubação chega a $75 \%$ da dosagem convencional. A partir desse ponto houve uma redução no crescimento provavelmente devido ao excesso de adubação, ocasionado pela retenção de nutrientes em função da presença do hidrogel, além do hidrogel provocar o aumento da condutividade elétrica e, consequentemente, aumento dos sais. Com a adição da adubação, essa concentração de sais provavelmente cause o excesso.

Comportamento semelhante ao obtido neste estudo foi descrito por Bernardi et al. (2012), os quais observaram que as mudas de Corymbia citriodora tiveram diminuição da altura com o uso superior a $60 \%$ da dose usual da adubação (6 $\left.\mathrm{g} \mathrm{L}^{-1}\right)$. Esta redução no desenvolvimento das mudas também é abordada por Vichiato et al. (2004), que destacam que os polímeros hidrorretentores também promovem o crescimento da planta quando nutrientes são incorporados ao substrato, liberandoos às plantas quando necessário. Entretanto, sob certas circunstâncias, sua adição tem tido pouca influência na performance das plantas, principalmente quando maiores quantidades de fertilizantes e sais estão presentes, devido à retenção de água, o que pode ocasionar excesso de nutrientes pela diminuição da lixiviação.

Destaca-se que alguns dos maiores valores em relação à altura das mudas ocorreram sob baixas dosagens de adubação quando se fez o uso do hidrogel. Houve bom desempenho em relação à altura inclusive na ausência de adubação, somente com o uso do hidrogel. O substrato utilizado possui uma pequena quantidade de nutrientes incorporados, mas que normalmente é insuficiente para nutrir as mudas durante todo período de permanência no viveiro.

O uso do hidrogel na ausência de adubação proporcionou um crescimento em altura similar à utilização de $75-100 \%$ da adubação na ausência do hidrogel, pois o hidrogel também possui a capacidade de liberar mais lentamente os nutrientes conforme a disponibilidade das mudas. Tittonell et al. (2002) verificaram que a adição de polímero ao substrato proporcionou maior precocidade, uniformidade e tamanho de plantas de pimentão, especialmente em solos carentes de nutrientes.

O diâmetro do coleto (DC) apresentou tendência similar em relação à altura, sendo que o DC mais elevado foi obtido na presença do hidrogel, e utilizando-se $57,7 \%$ da dose da adubação (Figura 
2B). Com o acréscimo da adubação, houve uma tendência de diminuição do diâmetro, quando se fez o uso do hidrogel. Já na ausência do hidrogel, o diâmetro do coleto foi aumentando com a dosagem, sendo observado o maior diâmetro com o uso de $124,5 \%$ da adubação.

A exemplo da altura das mudas foi observado um valor maior para o diâmetro do coleto sem a necessidade de adubação, somente fazendo o uso do hidrogel, ou em menores dosagens, como 25 e $50 \%$ da adubação convencional.

O diâmetro do coleto é, dentre as variáveis facilmente mensuradas, a mais promissora para indicar a qualidade das mudas (BINOTTO et al., 2010). Ainda, segundo Schmidt-Wogt (1984), o DC possui estreita correlação não somente com a sobrevivência, mas, sobretudo, com o ritmo de crescimento das mudas após o plantio.

Claramente, quando se fez uso do hidrogel, as doses acima do ponto de MET determinaram diminuição no crescimento das mudas, indicando que a possível redução no processo de lixiviação dos nutrientes aplicados, como resultado da atuação do polímero hidrorretentor, levou ao excesso dos elementos no substrato, diminuindo o diâmetro do coleto.

As fertilizações acima do máximo estimado $(57,7 \%)$ podem influenciar de forma negativa no diâmetro do coleto das mudas, havendo comportamento decrescente. Conforme Faquin (2002), é provável que isso ocorra devido ao efeito de excesso de nutrientes, causando toxidez ou deficiência induzida de outro nutriente. Ao se comparar a dose de $125 \%$ da dosagem de FLC com a testemunha, na presença de hidrogel, verificouse praticamente o mesmo valor para o diâmetro do coleto.

Tendências semelhantes quanto ao diâmetro do coleto de mudas de eucalipto produzidas com hidrogel $\left(6 \mathrm{~g} \mathrm{~L}^{-1}\right)$ foram encontradas por Bernardi et al. (2012), nas quais o diâmetro aumentou de forma progressiva com a adubação até o nível próximo a $60 \%$ da adubação, sendo que a dose que resultou no maior valor foi de 1,9 $\mathrm{g} \mathrm{L}^{-1}$ de FLC (19-6-10).

Alguns estudos utilizando FLC, sem o uso de hidrogel, mostraram resultados semelhantes a este estudo na produção de mudas de eucalipto. Menegassi et al. (2012) testando diferentes doses de FLC (18-06-12) em Eucalyptus citriodora, Eucalyptus dunnii e Eucalyptus grandis encontraram valores de altura e diâmetro de coleto muito próximos ao encontrado neste trabalho, também em avaliação realizada aos 90 dias após a semeadura. Conforme os autores, a dose de $7,5 \mathrm{~g} \mathrm{~L}^{-1}$ pode ser recomendada para a formação de mudas de eucalipto, tendo promovido os melhores resultados, propiciando mudas com melhor vigor. Moraes Neto et al. (2003) avaliando altura e diâmetro do coleto (DC), em Eucalyptus grandis, obtiveram resultados similares com a utilização de FLC na dose de $6,42 \mathrm{~g}$ $\mathrm{L}^{-1}$ de substrato aos 90 dias após a semeadura.

A massa seca da parte aérea (MSPA), massa seca radicular (MSR) e massa seca total (MST) resultaram em comportamento similar entre si (Figura 3), obtendo o maior valor com o uso do hidrogel e com adubação entre $50-100 \%$ da dose convencional. Na ausência do hidrogel, a maior massa (MSPA, MSR e MST) foi utilizando-se a dosagem de fertilizante entre $100-125 \%$.

A testemunha ( $0 \mathrm{~g} \mathrm{~L}^{-1}$ de adubo), bem como dosagens muito altas de adubo, ocasiona uma diminuição da massa seca. O suprimento insuficiente de nutrientes, ou de algum elemento essencial pode resultar em distúrbios metabólicos na planta, diagnosticados por sintomas de deficiência (TAIZ; ZEIGER, 2009), limitando seu crescimento e desenvolvimento. A disponibilidade total de nutrientes pode variar amplamente dentro de uma faixa adequada, sem efeito perceptível sobre o rendimento de matéria seca, ou seja, após a necessidade da planta ser atendida, uma fertilização maior não resultará em respostas no crescimento, caracterizando-se como "consumo de luxo", podendo também ocasionar toxicidade (LARCHER, 2006). Estas informações ratificam os resultados obtidos neste estudo.

Estas variáveis também demonstram que o hidrogel possibilita maior desenvolvimento das mudas, principalmente na ausência de adubação ou em menores dosagens. Já dosagens acima de 100\% causam diminuição da massa seca, tanto aérea como radicular. Este comportamento benéfico do uso dos hidrogéis, observado nessas variáveis, também é comentado por Azevedo et al. (2002), em que os autores mencionam que a presença de hidrogéis no solo otimiza a disponibilidade de água, reduz as perdas por percolação e lixiviação de nutrientes e melhora a aeração e drenagem do solo, acelerando o desenvolvimento do sistema radicular e da parte aérea das plantas.

Corroborando com os resultados deste estudo, Huttermann et al. (1997), analisando o sistema radicular das plantas de Pinus halepensis, verificaram que as mudas plantadas com hidrogel 

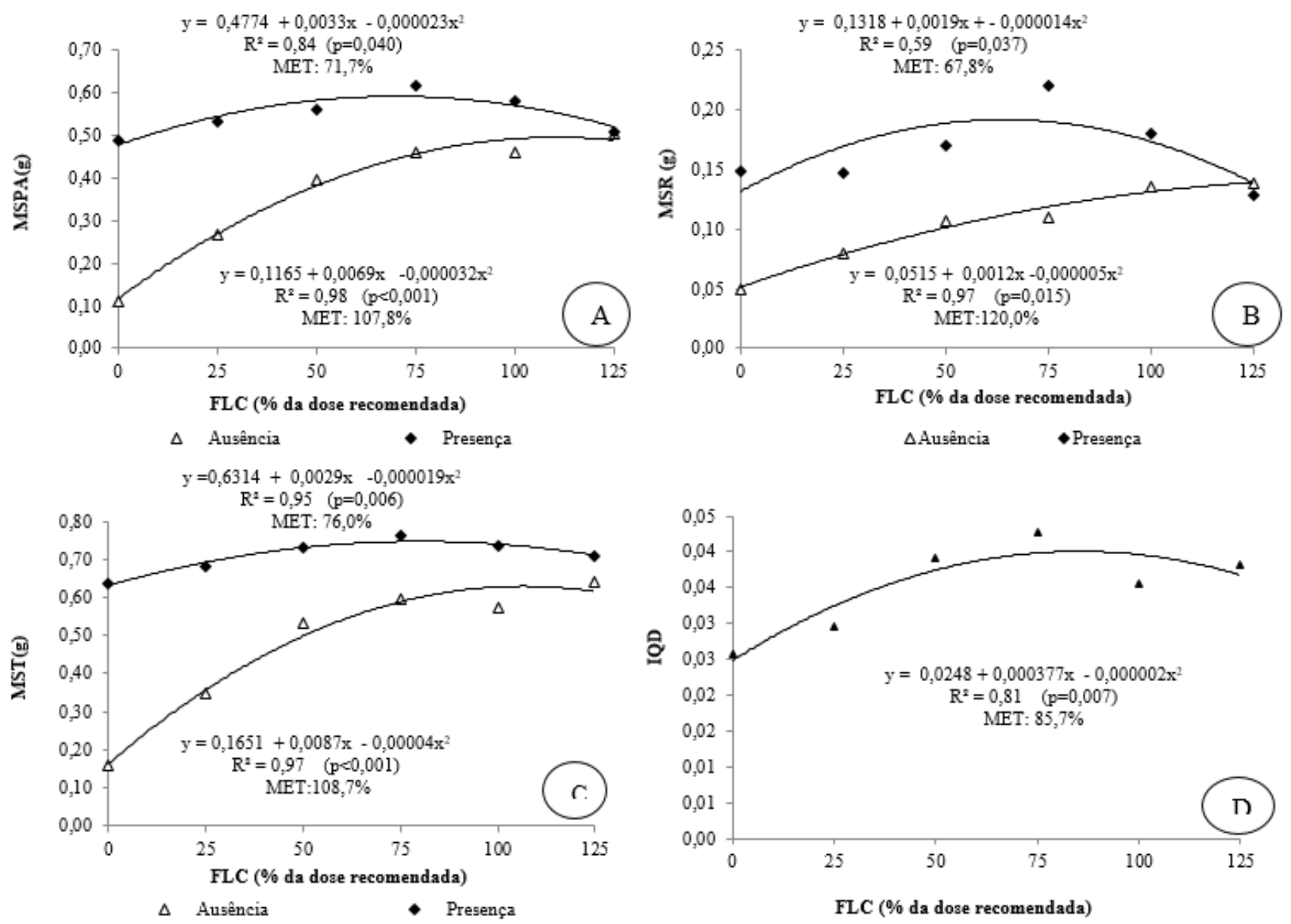

FIGURA 3: A - Massa seca da parte aérea - MSPA (g); B - massa seca radicular - MSR (g); C- massa seca total - MST (g) e D - Índice de Qualidade de Dickson (IQD) das mudas de Eucalyptus dunnii em função das doses de fertilizante (\% da dose convencional) na presença $\left(6 \mathrm{~g} \mathrm{~L}^{-1}\right)$ e ausência de hidrogel, aos 90 dias após semeadura.

FIGURE 3: A - Dry weight of shoot - MSPA (g), B - root biomass - MSR (g), C-total dry mass - MST (g) and D - Dickson Quality Index (IQD) of Eucalyptus dunnii seedlings depending on the fertilizer rates (\% of standard dose) in the presence $\left(6 \mathrm{~g} \mathrm{~L}^{-1}\right)$ and absence of hydrogel at 90 days after sowing.

no solo apresentaram maior quantidade de raízes adventícias e com mais ramificações em comparação ao sistema radicial das mudas não plantadas com o hidrogel.

A presença de maior quantidade de raízes também pode ajudar as mudas no período de transplante a campo. Thomas (2008) explicou que o hidrogel melhora a sobrevivência das mudas, pois permite que as raízes das plantas cresçam por dentro dos grânulos do polímero hidratado, com maior superfície de contato entre raízes, água e nutrientes.

Quanto ao índice de qualidade de Dickson, a presença do hidrogel misturado ao substrato ocasionou um valor maior $(0,042)$ em comparação à sua ausência $(0,028)$, diferenciando estatisticamente.
Quanto maior o índice de qualidade de Dickson, maior o diâmetro e a massa seca da parte aérea, indicando melhor grau de qualidade das mudas.

O IQD apresentou um comportamento quadrático (Figura 3D), obtendo-se o maior valor com o uso de $75 \%$ da dosagem do fertilizante de liberação controlada, tendendo a aumentar até a dose de máxima eficiência técnica $(85,7 \%)$. A ausência de adubação e a dosagem de $25 \%$ ocasionaram um baixo IQD e, o uso da dose recomendada (100\%) ou superior, indicam uma tendência de queda do índice, ou seja, diminuição da qualidade das mudas. O IQD é também uma variável utilizada para indicar a qualidade de mudas, pois se relaciona com a maioria das variáveis estudadas (BINOTTO; 


\section{LÚCIO; LOPES, 2010).}

Em geral, o uso do polímero $\left(6 \mathrm{~g} \mathrm{~L}^{-1}\right)$ permite a redução em, pelo menos, $25 \%$ da adubação convencional, podendo atingir até $50 \%$ dependendo da variável observada. A tendência de economia de adubo com o uso do hidrogel, produzindo mudas de boa qualidade é confirmada por Cotthem (1998). Segundo o autor, pela capacidade de reter nutrientes, os polímeros contribuem diretamente para a nutrição da planta e podem reduzir o consumo de fertilizantes em 20 a $50 \%$ e as ações dos fertilizantes podem ser aumentadas devido às características hidrofílicas e seus grupos funcionais ionizáveis.

\section{CONCLUSÕES}

$\mathrm{O}$ uso do hidrogel de poliacrilamida apresenta melhoria das características químicas e físicas dos substratos, principalmente aos atributos que envolvem armazenamento e disponibilização de água às plantas.

O uso do polímero hidrorretentor na produção de mudas de Eucalyptus dunnii pode reduzir o uso de adubação em 25 a $50 \%$, em média, não havendo prejuízo na qualidade das mudas.

\section{REFERÊNCIAS BIBLIOGRÁFICAS}

ABAD, M.; MARTINEZ, P. F.; MARTINEZ, J. Evaluación agrónomica de los substratos de cultivo. Actas de Horticultura, Villaviciosa, Espanha, v. 11, p. 141-154, 1993.

AZEVEDO, T. L. F.; BERTONHA, A.; GONÇALVES, A. C. A. Uso de Hidrogel na Agricultura. Revista do Programa de Ciências Agro-Ambientais, Alta Floresta, v. 1, n. 1, p. 23-31, 2002.

AZEVEDO, T. L. F. et al. Níveis de polímero superabsorvente, frequência de irrigação e crescimento de mudas de café. Acta Scientiarum, Maringá, v. 24, n. 5, p. 1239-1243, 2002.

BERNARDI, M. R. et al. Crescimento de mudas de Corymbia citriodora em função do uso de hidrogel e adubação. Cerne, Lavras, v. 18, n. 1, p. 67-74, 2012.

BINOTTO, A. F.; LÚCIO, A. D.; LOPES, S. J. Correlations between growth variables and the dickson quality índex in forest seedlings. Cerne, Lavras, v. 16, n. 4, p. 457-464, 2010.

BRASIL. Ministério da Agricultura, Pecuária e Abastecimento (MAPA). Instrução Normativa SDA $\mathrm{N}^{\mathrm{o}}$ 17. Métodos Analíticos Oficiais para Análise de
Substratos para Plantas e Condicionadores de Solo. Diário Oficial da União, Brasília, 24 maio 2007. Seção 1.

COTTHEM, W. V. O papel de Terracottem como um absorvente universal. Ghent: [s. n.], 1998.

DICKSON, A. et al. Quality appraisal of white spruce and white pine seedling stock in nurseries. Forest Chronicle, Mattawa, v. 36, p. 10-13, 1960.

FAGERIA, N. F. Otimização da eficiência nutricional na produção das culturas. Revista Brasileira de Engenharia Agrícola e Ambiental, Campina Grande, v. 2, n. 1, p. 6-16, 1998.

FAQUIN, V. Diagnose do estado nutricional das plantas. 2002. 77 f. Monografia (Especialização fertilidade do solo e nutrição de plantas no agronegócio) - Universidade Federal de Lavras/ FAEPE, Lavras, 2002.

FERMINO, M. H. Métodos de análise para caracterização de física de substratos. 2003. 89 f. Tese (Doutorado em Fitotecnia) Universidade Federal do Rio Grande do Sul, Porto Alegre, 2003.

FERREIRA, D. F. Sisvar: a computer statistical analysis system. Ciência e Agrotecnologia, Lavras, v. 35, n. 6, p. 1039-1042, 2011.

FLANNERY, R. L.; BUSSCHER, W. J. Use of a synthetic polymer in potting soil to improve water holding capacity. Communication in Soil Science Plant, London, v. 13, n. 2, p. 103-111, 1982.

GEESING, D.; SCHMIDHALTER, U. Influence of sodium polycrylate on the water-holding capacity of three different soils and effects on growth of wheat. Soil Use and Management, Hoboken, v. 20, p. 207-209, 2004.

GONÇALVES, J. L.M.; POGGIANI, F. Substrato para produção de mudas. (Compact disc). In: CONGRESSO LATINO AMERICANO DE CIÊNCIA DO SOLO, 13., 1996, Águas de Lindóia. Anais... Águas de Lindóia: SLCS; SBCS; ESALQ/ USP; CEA; SBM, 1996.

GONÇALVES, J. L. M. et al. Produção de mudas de espécies nativas: substrato, nutrição, sombreamento e fertilização. In: CONGRESSO LATINO AMERICANO DE CIÊNCIA DO SOLO, 13., 1996; BENEDETTI, V. (Eds.). Nutrição e fertilização florestal. Piracicaba: IPEF, 2000. p. 309-350.

HAASE, D. Understanding forest seedling quality: measurements and interpretation. Tree Planter's Notes, Washington, DC, v. 52, n. 2, p. 24-30, 2008. HUTTERMANN, A.; ZOMMORODI, M.; WANG, S. The use of Hydrogels for afforestations of difficult stands: Water and salt stress. Affoerestation 
in semi-arid regions-Findings and Perspectives. In: INTERNATIONAL SYMPOSIUM IN THE PEOPLES REPUBLIC OF CHINA, 1997. Proceedings ... 1997. p. 167-174.

KÄMPF, A. N. Produção comercial de plantas ornamentais. 2. ed. Guaíba: Agrolivros, 2005. $256 \mathrm{p}$.

LANDIS, T. D. Mineral nutrients and fertilization. In: INTERNATIONAL SYMPOSIUM IN THE PEOPLES REPUBLIC OF CHINA, 1997. The container tree nursery manual: agriculture handbook 674. Washington, D.C.: U.S. Department of Agriculture, Forest Service, 1989. v. 4, p. 1-67.

LARCHER W. Ecofisiologia vegetal. São Carlos: RIMA, 2006.

MENEGASSI, A. D. et al. Produção de mudas de eucalipto sob diferentes fontes de adubação. In: CONGRESSO FLORESTAL PARANAENSE, 4., 2012, Curitiba. Anais... Curitiba: UFPR, 2012.

MORAES NETO, S. P. et al. Produção de mudas de espécies arbóreas nativas com combinações de adubos de liberação controlada e prontamente solúveis. Revista Árvore, Viçosa, v. 27, n. 6, p. 779-789, 2003.

OLIET, J. et al. Los fertilizantes de liberacion controlada lenta aplicados a la produccion de planta forestal de vivero. Efecto de dosis y formulaciones sobre la calidad de Pinus halepensis mil. Investigación Agraria: Sistemas y Recursos Forestales, Madrid, v. 8, n. 1, p. 207-228, 1999.

PALUDZYSZYN FILHO, E.; SANTOS, P. E. T.; FERREIRA, C. A. Eucaliptos indicados para plantio no Estado do Paraná. Colombo: Embrapa Florestas, 2006. 45 p. (Documentos, 129).

PETERSON, D. Hydrophilic polymers: effects and uses in the landscape. Soviet Soil Science, Moscow, v. 13, n. 4, p. 111-115, 2003.

PREVEDELLO, C. L.; BALENA, S. P. Efeitos de polímeros hidrorretentores nas propriedades físicohídricas de dois meios porosos. Revista Brasileira de Ciência do Solo, Viçosa, MG, v. 24, n. 2, p. 251-258, 2000.

RÖBER, R.; SCHALLER, K. Pflanzenernährung im Gartenbau. Stuttgart: Ulmer, 1985. 352 p.

SCHMIDT-VOGT, H. Morpho-physiological quality of forest tree seedlings: the present international status of research. In: SIMPÓSIO INTERNACIONAL SOBRE MÉTODOS DE PRODUÇÃO E CONTROLE DE QUALIDADE
DE SEMENTES E MUDAS FLORESTAIS, 1984, Curitiba. Anais... Curitiba: UFPR/FUPEF, 1984. p. 366-378.

SGARBI, F. et al. Influência da aplicação de fertilizante de liberação controlada na produção de mudas de um clone de Eucalyptus urophylla. In: SIMPÓSIO SOBRE FERTILIZAÇÃO E NUTRIÇÃO FLORESTAL, 2., 1999, Piracicaba. Anais... Piracicaba: IPEF/ESALQ, 1999. p. $120-125$.

SHAVIV, A. Advances in controlled-release fertilizers. Advances in Agronomy, San Diego, v. 71, p. 1-49, 2001.

TAIZ, L.; ZEIGER, E. Fisiologia vegetal. 4. ed. Porto Alegre: Artmed, 2009. 848 p.

TAYLOR, K. C.; HALFACRE, R. G. The effect of hydrophilic polymer on media water retention and nutrient availability to Ligustrum lucidum. Horticulture Science, Praha, v. 21, p. 1159-1161, 1986.

THOMAS, D. S. Hydrogel applied to the root plug of subtropical eucalypt seedlings halves transplant death following planting. Forest Ecology and Management, Amsterdam, v. 255, n. 3-4, p. 1305-1314, 2008.

TITTONELL, P. A.; GRAZIA, J.; CHIESA, A. Adición de polímeros superabsorbentes en el medio de crecimiento para la producción de plantines de pimiento. Horticultura Brasileira, Brasília, v. 20, n. 4, p. 641-645, 2002.

VALERI, S. V.; CORRADINI, L. Fertilização em viveiros para a produção de mudas de Eucalyptus e Pinus. In: GONÇALVES, J. L. M.; BENEDETTI, V. Nutrição e fertilização florestal. Piracicaba: IPEF, 2000. p. 167-190.

VICHIATO, M. et al. Crescimento e composição mineral do porta-enxerto de tangerina Cleópatra cultivado em substrato acrescido de polímero hidroretentor. Ciência Agropecuária, Lavras, v. 28, n. 4, p. 748-756, 2004.

WENDLING, I.; DUTRA, L. F.; GROSSI, F. Produção de mudas de espécies lenhosas. Colombo: Embrapa Florestas, 2006. (Documentos 130).

ZANETTI, M. et al. Efeito de diferentes concentrações de citocinina na brotação de gemas de laranjeira Valência sobre limoeiro Cravo e citrumeleiro Swingle. Brazilian Journal of Plant of Plant Physiology, Campinas, v. 15, supl, p. 223, 2003. 